\title{
Neuromyelitis optica spectrum disorders without and with autoimmune diseases
}

\author{
Bingjun Zhang ${ }^{1 \dagger}$, Yi Zhong ${ }^{2 \dagger}$, Yanqiang Wang ${ }^{1 \dagger}$, Yongqiang Dai', Wei Qiu', Lei Zhang ${ }^{1}$, Haiyan Li $^{1}$ \\ and Zhengqi Lu ${ }^{1 *}$
}

\begin{abstract}
Background: Neuromyelitis optica spectrum disorder (NMOSD) can coexist with non-organ-specific or organ-specific autoimmune diseases. The aim of this study was to investigate and compare the features between NMOSD without and with autoimmune diseases, and NMOSD with non-organ-specific and organ-specific autoimmune diseases.

Methods: One hundred and fifty five NMOSD patients without autoimmune diseases $(n=115)$ and with autoimmune diseases $(n=40)$ were enrolled. NMOSD with autoimmune diseases were divided by organ-specific autoimmune diseases. The clinical, laboratory and magnetic resonance imaging features between two groups were assessed.

Results: Motor deficit was less frequent in NMOSD patients with non-organ-specific autoimmune diseases ( $p=0.024)$. Cerebrospinal fluid white blood cell and protein, serum C-reactive protein and immunoglobulin G were lower in NMOSD patients without autoimmune diseases, while several autoantibodies seropositivity and thyroid indexes were significantly higher in NMOSD patients with autoimmune diseases $(p<0.05)$. No difference was found in other clinical and laboratory characteristics between different NMOSD subtypes $(p>0.05)$. NMOSD patients with autoimmune diseases had higher brain abnormalities than NMOSD without autoimmune diseases $(p<0.001)$.
\end{abstract}

Conclusions: The characteristics between NMOSD without and with autoimmune diseases were similar. NMOSD with autoimmune diseases have high frequency of brain abnormalities.

Keywords: Neuromyelitis optica, Neuromyelitis optica spectrum disorder, Non-organ-specific autoimmune diseases, Organ-specific autoimmune diseases, Autoantibodies, Magnetic resonance imaging

\section{Background}

Neuromyelitis optica (NMO) is a severe demyelinating disease of the central nervous system that affects the optic nerve and spinal cord but has protean and diverse potential clinical and radiological manifestations [1-3]. The broadened array of disorders associated with NMO immunoglobulin G (IgG) has been termed 'NMO spectrum disorders' (NMOSD), the diagnosis of which is greatly facilitated by the association of NMOSD with a specific biomarker for NMO, NMO-IgG [1]. Several groups have recognized a strong association of NMOSD with nonorgan-specific autoimmune diseases (e.g. systemic lupus erythematosus (SLE), Sjögren syndrome (SS), rheumatoid

\footnotetext{
* Correspondence: Izqzssy@gmail.com

${ }^{\dagger}$ Equal contributors

'Department of Neurology, The Third Affiliated Hospital of Sun Yat-sen University, No 600 Tianhe Road, Guangzhou, Guangdong 510630, China Full list of author information is available at the end of the article
}

arthritis (RA), undifferentiated connective tissue disease (UCTD)), and organ-specific autoimmune diseases (e.g. thyroid diseases, myasthenia gravis) [4-6]. However, few systemic studies have focused on the relationship between NMOSD without and with autoimmune diseases, and NMOSD with non-organ-specific and organ-specific autoimmune diseases. The characteristics of different NMOSDs, particularly NMOSD with non-organ-specific and organspecific autoimmune diseases, were not studied enough. In this study, we investigated and compared the clinical, laboratory and magnetic resonance imaging (MRI) features between NMOSD without and with autoimmune diseases. Furthermore, the characteristics of NMOSD with non-organ-specific and organ-specific autoimmune diseases were also investigated.

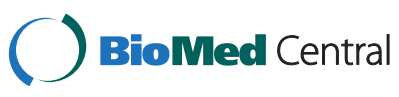

(c) 2014 Zhang et al.; licensee BioMed Central Ltd. This is an Open Access article distributed under the terms of the Creative Commons Attribution License (http://creativecommons.org/licenses/by/4.0), which permits unrestricted use, distribution, and reproduction in any medium, provided the original work is properly credited. The Creative Commons Public Domain Dedication waiver (http://creativecommons.org/publicdomain/zero/1.0/) applies to the data made available in this article, unless otherwise stated. 


\section{Methods \\ Patients}

Our database comprised 170 Chinese patients with NMOSD who were diagnosed and admitted from March 1, 2002 to March 1, 2013 in the MS Center of the Third Affiliated Hospital of Sun Yat-sen University, Guangzhou, China. NMO was diagnosed according to the 2006 Wingerchuk criteria [2]. In addition, NMOSD was diagnosed according to the 2007 Wingerchuk criteria [1]. Other included were: (a) all of these patients whose serum samples were tested for NMO-IgG, autoreactive antibodies (antinuclear antibodies (ANAs), extractable nuclear antigen autoantibodies (ENAs), rheumatoid factors (RFs) anti-neutrophil cytoplasmic antibodies (ANCAs)), immunoglobulins, complements, thyroid hormones and autoantibodies; and (b) also MRI of the brain and spinal cord available for review. Non-organ-specific autoimmune diseases (e.g. SLE [7], SS [8], RA [9], UCTD [10]), and organ-specific autoimmune diseases (e.g. thyroid diseases) were diagnosed by neurologists/rheumatologists/endocrinologists according to the criteria and typology guidelines. Clinical data and MRI scans were collected from these individuals, a group that including 115 NMOSD patients without autoimmune diseases and 40 with autoimmune diseases (20 with non-organ-specific autoimmune diseases and 18 with organ-specific autoimmune diseases).

This study was approved by the local Ethics Committee of the Third Affiliated Hospital of Sun Yat-sen University. Informed consents for this investigation were obtained from the patients or their family members.

\section{Laboratory testing}

Blood and cerebrospinal fluid (CSF) samples were obtained from all the patients in our study during hospital admission. All profiling for each patient was performed using commercially clinical laboratory assays. CSF oligoclonal banding (OCB) and NMO-IgG were tested in our clinical neuroimmunological Laboratory. Autoreactive antibodies (ANAs, ENAs, RFs, ANCAs) testing were performed at the clinical rheumatology immunology laboratory of Sun Yat-sen University. The immunoglobulins, complements, thyroid indexes, and other profiling were tested in the clinical laboratory of Sun Yat-sen University.

\section{Magnetic resonance imaging}

Brain and spinal cord MRI scans were performed in all patients using a GE 1.5 T MR scanner (General Electric, Milwaukee, Wisconsin, USA). The slice thickness of the axial scans was $5 \mathrm{~mm}$. Conventional MRI protocols were used in all patients: T1 with and without gadolinium enhancement (400/15.5 ms, TR/TE) and T2 (2500- 3500/ $100 \mathrm{~ms}, \mathrm{TR} / \mathrm{TE}$ ) for spinal cord MRI; and T1 with and without gadolinium enhancement (2128-2300/11.6$12.4 \mathrm{~ms}, \mathrm{TR} / \mathrm{TE}), \mathrm{T} 2$ (4600-4640/97.8-102 ms, TR/TE), and fluid-attenuated inversion recovery (FLAIR) (8800/ $120 \mathrm{~ms}, \mathrm{TR} / \mathrm{TE}$ ) for brain MRI. Each patient underwent MRI scanning at the time of the initial diagnosis, prior to corticosteroid treatment. No patients were receiving immunomodulatory treatment at the time of the MRI scanning. The numbers, locations, and diameters of lessions were recorded. All image archives were reviewed with a DICOM viewer on a Macintosh computer. An experienced neuroradiologist and a neurologist, both of whom were blinded to the diagnostic categorization and the patients' clinical features, each analyzed all of the MRI scans. The final assessments were made by consensus.

\section{Statistical analysis}

Statistical analysis was performed by SPSS version 22.0. Values of $p=0.05$ were considered statistically significant. Quantitative data were processed using the Mann-Whitney U-test or Student's t-test. All quantitative data in this study are presented as mean \pm standard deviation (SD) or median (range). Qualitative data were analyzed with the $\chi^{2}$ test or Fisher's exact test. Power calculations indicated these were $80 \%$ power to detect $9.7 \%(n=155)$ and $27.6 \%$ $(n=40)$ differences in the percentage of features, with alpha set at 0.05 .

\section{Results}

The data of 170 patients with NMOSD were reviewed between 2002 and 2013. A total of 155 patients satisfied the diagnostic criteria for inclusion in this study: 115 NMOSD patients without autoimmune diseases and 40 with autoimmune diseases (22 NMOSD patients with non-organ-specific autoimmune diseases and 18 NMOSD patients with organ-specific autoimmune diseases). The details of the enrollment process can be seen in the flowchart (Figure 1).

The demographic and clinical features of the patients are summarized in Table 1. There were no statistical differences in demographic and clinical characteristics between NMOSD without and with autoimmune diseases $(p>0.05)$. After further analysis, motor deficit was less frequent in NMOSD patients with non-organ-specific autoimmune diseases than in NMOSD patients with organspecific autoimmune diseases $(p=0.024)$. No difference was found in other demographic and clinical features between NMOSD patients with non-organ-specific autoimmune diseases and NMOSD patients with organ-specific autoimmune diseases $(\mathrm{p}>0.05)$.

The laboratory features of the patients are summarized in Table 2. CSF white blood cell (WBC) and protein were significantly lower in NMOSD patients without autoimmune diseases than in NMOSD patients with autoimmune diseases $(p<0.05)$, while CSF glucose was significantly higher in NMOSD patients without autoimmune diseases than in NMOSD patients with autoimmune diseases $(\mathrm{p}=0.012)$. 


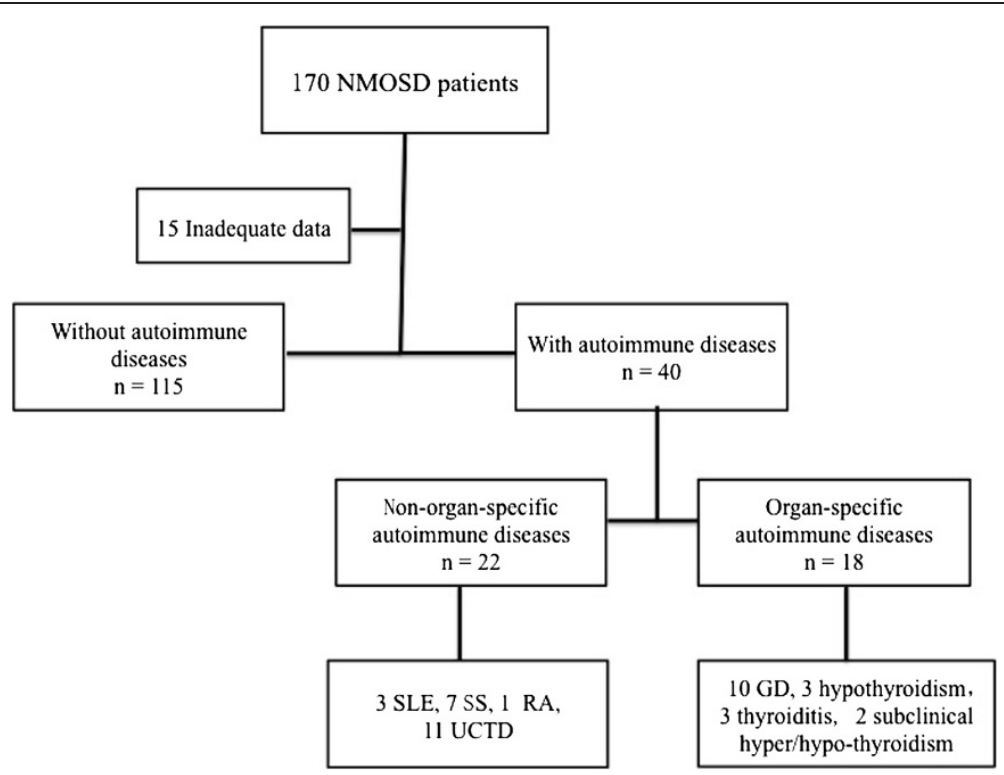

Figure 1 Study flowchart. Abbreviations: SLE = systemic lupus erythematosus; SS = Sjögren syndrome; RA = rheumatoid arthritis; UCTD = undifferentiated connective tissue disease; GD = Graves' disease.

Serum C-reactive protein (CRP) was significantly lower in NMOSD patients without autoimmune diseases than NMOSD patients with autoimmune diseases $(p=0.017)$. Furthermore, ANA, anti-SSA/Ro antibodies (SSA), antiSSB/La antibodies (SSB), anti-double stranded DNA antibodies (Ds-DNA), anti-nucleosome antibody (AnuA),
anti-Sm antibodies (Sm) seropositivity, and serum IgG were significantly lower in NMOSD patients without autoimmune diseases than in NMOSD patients with autoimmune diseases $(\mathrm{p}<0.05)$, while anti-thyroglobulin antibodies (TG) seropositivity, thyroxin (T4), and free thyroxin (FT4) were significantly higher in NMOSD

Table 1 Demographic and clinical characteristics between NMOSD without and with autoimmune diseases, and between NMOSD with non-organ-specific and organ-specific autoimmune diseases

\begin{tabular}{|c|c|c|c|c|c|c|}
\hline & \multicolumn{2}{|l|}{ NMOSD } & \multirow[b]{2}{*}{$\mathbf{P}$} & \multicolumn{2}{|c|}{ NMOSD with autoimmune diseases } & \multirow[b]{2}{*}{$\mathbf{P}$} \\
\hline & $\begin{array}{l}\text { Without autoimmune } \\
\text { diseases }(n=115)\end{array}$ & $\begin{array}{l}\text { With autoimmune } \\
\text { diseases }(n=40)\end{array}$ & & Non-organ-specific $(n=22)$ & Organ-specific $(n=18)$ & \\
\hline Gender, F: M & 91: 24 & $37: 3$ & 0.055 & 22: 0 & $15: 3$ & 0.165 \\
\hline Age, years & $37.63 \pm 14.33$ & $40.71 \pm 13.80$ & 0.240 & $40.90 \pm 14.86$ & $40.47 \pm 12.80$ & 0.924 \\
\hline Age at onset, years & $34.20 \pm 13.70$ & $37.37 \pm 13.50$ & 0.207 & $36.91 \pm 14.63$ & $37.94 \pm 12.37$ & 0.814 \\
\hline Disease duration, years & $1.83(0.08,30.00)$ & $1.33(0.08,31.08)$ & 0.219 & $1.25(0.08,31.08)$ & $2.67(0.08,7.00)$ & 0.414 \\
\hline Annualized relapse rate & $0.66(0,12.00)$ & $0.89(0,6.00)$ & 0.183 & $0.80(0,3.43)$ & $0.95(0,6.00)$ & 0.784 \\
\hline EDSS at last visit & $2.0(0,23.0)$ & $2.5(0,10.0)$ & 0.067 & $2.5(1.0,8.5)$ & $3.0(0,10.0)$ & 0.529 \\
\hline \multicolumn{7}{|l|}{ Clinical features, n (\%) } \\
\hline Headache & $18(15.7 \%)$ & $8(20.0 \%)$ & 0.526 & $3(13.6 \%)$ & $5(27.8 \%)$ & 0.475 \\
\hline Nystagmus & $6(5.2 \%)$ & $4(10.0 \%)$ & 0.289 & $2(9.1 \%)$ & $2(11.1 \%)$ & 0.832 \\
\hline $\mathrm{HN}$ & $26(22.6 \%)$ & $12(30.0 \%)$ & 0.349 & $4(18.2 \%)$ & $8(44.4 \%)$ & 0.071 \\
\hline Bulbar paralysis & $9(7.8 \%)$ & $2(5.0 \%)$ & 0.549 & $1(4.5 \%)$ & $1(5.6 \%)$ & 1.000 \\
\hline Bowel or bladder dysfunction & $49(42.6 \%)$ & $18(45.0 \%)$ & 0.793 & $7(31.8 \%)$ & $11(61.1 \%)$ & 0.064 \\
\hline Visual impairment & $98(85.2 \%)$ & $33(82.5 \%)$ & 0.682 & $18(81.8 \%)$ & $15(83.3 \%)$ & 0.900 \\
\hline Motor deficit & $68(59.1 \%)$ & $21(52.5 \%)$ & 0.465 & $8(36.4 \%)$ & $13(72.2 \%)$ & $0.024^{*}$ \\
\hline Sensory deficit & $83(72.2 \%)$ & $25(62.5 \%)$ & 0.252 & $14(63.6 \%)$ & $11(61.1 \%)$ & 0.870 \\
\hline Neuropathic pain & $29(25.4 \%)$ & $13(32.5 \%)$ & 0.388 & $6(27.3 \%)$ & 7 (38.9\%) & 0.435 \\
\hline
\end{tabular}

Abbreviations: EDSS Expanded Disability Status Scale, F: M female: male, IHN intractable hiccup and nausea, NMOSD neuromyelitis optica spectrum disorders. ${ }^{*} \mathrm{p}<0.05$. 
Table 2 Laboratory features between NMOSD without and with autoimmune diseases, and between NMOSD with non-organ-specific and organ-specific autoimmune diseases

\begin{tabular}{|c|c|c|c|c|c|c|}
\hline & \multicolumn{2}{|l|}{ NMOSD } & \multirow[b]{2}{*}{$\mathbf{P}$} & \multicolumn{2}{|c|}{ NMOSD with autoimmune diseases } & \multirow[b]{2}{*}{$\mathbf{P}$} \\
\hline & $\begin{array}{l}\text { Without autoimmune } \\
\text { diseases }(n=115)\end{array}$ & $\begin{array}{l}\text { With autoimmune } \\
\text { diseases }(n=40)\end{array}$ & & Non-organ-specific $(n=22)$ & Organ-specific $(n=18)$ & \\
\hline \multicolumn{7}{|l|}{ CSF Index } \\
\hline WBC $\left(10^{6}\right)$ & $6(0,140)$ & $10(0,48)$ & $0.002^{*}$ & $12(2,48)$ & $9.5(0,46)$ & 0.307 \\
\hline Protein $(\mathrm{g} / \mathrm{l})$ & $0.22(0.06,1.64)$ & $0.27(0.12,0.80)$ & $0.017^{*}$ & $0.27(0.19,0.80)$ & $0.32(0.12,0.72)$ & 0.754 \\
\hline Glucose $(\mathrm{mmol} / \mathrm{l})$ & $3.47 \pm 0.70$ & $3.11 \pm 0.94$ & $0.012^{*}$ & $2.88 \pm 0.23$ & $3.41 \pm 1.59$ & 0.075 \\
\hline Chloride (mmol/l) & $126.3 \pm 5.1$ & $126.6 \pm 2.8$ & 0.657 & $126.3 \pm 6.9$ & $127.0 \pm 9.7$ & 0.434 \\
\hline OCB, n (\%) & $6(5.2 \%)$ & $3(7.5 \%)$ & 0.595 & $2(9.1 \%)$ & $1(5.6 \%)$ & 1.000 \\
\hline \multicolumn{7}{|l|}{ Serums Index } \\
\hline CRP $(\mathrm{mg} / \mathrm{l})$ & $2.33 \pm 4.37$ & $5.63 \pm 7.62$ & $0.001^{*}$ & $2.16(0.00,26.09)$ & $0.80(0.10,15.00)$ & 0.289 \\
\hline $\operatorname{ESR}(\mathrm{mm} / \mathrm{H})$ & $12.90 \pm 7.89$ & $14.04 \pm 13.39$ & 0.519 & $10.5(1.3,50.0)$ & $7.00(3.0,24.0)$ & 0.414 \\
\hline NMO-lgG, n (\%) & 71 (67.0\%) & $32(80.0 \%)$ & 0.120 & 18 (81.8\%) & $14(77.8 \%)$ & 0.751 \\
\hline ANA, n (\%) & 16 (13.9\%) & $20(50.0 \%)$ & $<0.001^{* *}$ & 18 (81.8\%) & $2(11.1 \%)$ & $<0.001^{* *}$ \\
\hline SSA, n (\%) & $2(1.7 \%)$ & $20(50.0 \%)$ & $<0.001^{* *}$ & 20 (90.9\%) & $0(00.0 \%)$ & $<0.001^{* *}$ \\
\hline SSB, n (\%) & $1(0.9 \%)$ & $11(27.5 \%)$ & $<0.001^{* *}$ & $11(50.0 \%)$ & $0(00.0 \%)$ & $0.002^{*}$ \\
\hline RF, n (\%) & $2(1.7 \%)$ & $3(7.5 \%)$ & 0.075 & $2(9.10 \%)$ & $1(5.60 \%)$ & 1.000 \\
\hline Ds-DNA, n (\%) & $0(0.0 \%)$ & $5(12.5 \%)$ & $0.001^{*}$ & $5(22.7 \%)$ & $0(00.0 \%)$ & 0.053 \\
\hline AnuA, n (\%) & $0(0.0 \%)$ & $3(7.5 \%)$ & $0.021^{*}$ & $3(13.6 \%)$ & $0(00.0 \%)$ & 0.305 \\
\hline $\mathrm{AHA}, \mathrm{n}(\%)$ & $0(0.0 \%)$ & $1(2.5 \%)$ & 0.579 & $1(4.5 \%)$ & $0(00.0 \%)$ & 1.000 \\
\hline RNP, n (\%) & $0(0.0 \%)$ & $2(5.0 \%)$ & 0.110 & $2(9.1 \%)$ & $0(00.0 \%)$ & 0.492 \\
\hline Sm, n (\%) & $0(0.0 \%)$ & $3(7.5 \%)$ & $0.021^{*}$ & $3(13.6 \%)$ & $0(00.0 \%)$ & 0.305 \\
\hline Jo-1, n (\%) & $0(00.0 \%)$ & $0(00.0 \%)$ & - & $0(00.0 \%)$ & $0(00.0 \%)$ & - \\
\hline Scl-70, n (\%) & $0(00.0 \%)$ & $0(00.0 \%)$ & - & $0(00.0 \%)$ & $0(00.0 \%)$ & - \\
\hline ANCA, n (\%) & $0(00.0 \%)$ & $0(00.0 \%)$ & - & $0(00.0 \%)$ & $0(00.0 \%)$ & - \\
\hline Rib-P, n (\%) & $0(0.0 \%)$ & $2(5.0 \%)$ & 0.110 & $2(9.1 \%)$ & $0(00.0 \%)$ & 0.492 \\
\hline AKA, n (\%) & $0(00.0 \%)$ & $0(00.0 \%)$ & - & $0(00.0 \%)$ & $0(00.0 \%)$ & - \\
\hline RA33, n (\%) & $0(00.0 \%)$ & $0(00.0 \%)$ & - & $0(00.0 \%)$ & $0(00.0 \%)$ & - \\
\hline CCP, n (\%) & $0(00.0 \%)$ & $0(00.0 \%)$ & - & $0(00.0 \%)$ & $0(00.0 \%)$ & - \\
\hline $\lg G(g / l)$ & $12.46 \pm 4.95$ & $18.33 \pm 0.82$ & $<0.001^{* *}$ & $14.18(7.00,38.80)$ & $12.61(7.00,33.22)$ & 0.765 \\
\hline $\lg A(g / l)$ & $1.41 \pm 0.40$ & $1.51 \pm 4.95$ & 0.310 & $1.30(0.45,3.60)$ & $1.28(0.56,2.15)$ & 0.142 \\
\hline $\lg M(g / l)$ & $1.15 \pm 0.37$ & $1.06 \pm 0.38$ & 0.169 & $1.14(0.45,1.75)$ & $0.97(0.58,1.99)$ & 0.454 \\
\hline C3 (g/l) & $1.09 \pm 0.24$ & $1.04 \pm 0.39$ & 0.334 & $1.06 \pm 0.17$ & $1.01 \pm 0.13$ & 0.667 \\
\hline C4 (g/l) & $0.23 \pm 0.15$ & $0.19 \pm 0.15$ & 0.116 & $0.15(0.04,0.93)$ & $0.15(0.03,0.32)$ & 0.935 \\
\hline $\mathrm{CH} 50(\mathrm{U} / \mathrm{ml})$ & $44.11 \pm 12.80$ & $39.60 \pm 17.12$ & 0.082 & $41.50(10.00,66.00)$ & $33.00(19.00,61.00)$ & 0.549 \\
\hline TPO (U/ml) & $54.46 \pm 72.57$ & $86.02 \pm 124.90$ & 0.055 & $29.3(5.7,60.0)$ & $99.9(11.7,533.1)$ & $0.019^{*}$ \\
\hline $\mathrm{TG}(\mathrm{U} / \mathrm{ml})$ & $42.82 \pm 54.46$ & $91.83 \pm 127.25$ & $0.001^{*}$ & $34.05(10.11,97.14)$ & $82.10(1.99,500.00)$ & $0.003^{*}$ \\
\hline T3 (nmol/l) & $1.96 \pm 1.60$ & $4.01 \pm 13.72$ & 0.114 & $1.99(0.66,2.45)$ & $1.20(0.70,88.08)$ & 1.000 \\
\hline T4 (nmol/l) & $97.47 \pm 25.95$ & $120.95 \pm 65.17$ & $0.002^{*}$ & $106.5(76.9,170.0)$ & $94.8(11.7,363.6)$ & 0.765 \\
\hline FT3 $(p m o l / l)$ & $4.07 \pm 0.97$ & $4.45 \pm 3.31$ & 0.273 & $4.16(2.59,5.47)$ & $3.89(1.03,23.98)$ & 0.903 \\
\hline
\end{tabular}


Table 2 Laboratory features between NMOSD without and with autoimmune diseases, and between NMOSD with non-organ-specific and organ-specific autoimmune diseases (Continued)

\begin{tabular}{|c|c|c|c|c|c|c|}
\hline FT4 (pmol/l) & $15.62 \pm 4.67$ & $20.21 \pm 15.91$ & $0.006^{*}$ & $17.06(10.89,22.92)$ & $17.18(8.60,99.25)$ & 0.663 \\
\hline TSH (ulU/ml) & $1.91 \pm 2.48$ & $2.85 \pm 6.05$ & 0.169 & $1.93(0.42,4.02)$ & $0.98(0.01,36.50)$ & 0.149 \\
\hline \multicolumn{7}{|c|}{$\begin{array}{l}\text { Abbreviations: } A H A \text { anti-histone antibody, AKA anti-keratin antibodies, ANA antinuclear antibodies, ANCA anti-neutrophil cytoplasmic antibodies, ANuA anti-nucleosome } \\
\text { antibody, C complements, CCP anti-cytosolic carboxypeptidase antibodies, CH50 50\% complement hemolysis, CRP C-reactive protein, CSF cerebrospinal fluid, Ds-DNA } \\
\text { anti-double stranded DNA antibodies, ESR erythrocyte sedimentation rate, FT3 free triiodothyronine, FT4 free thyroxin, IgG immunoglobulin G, Jo-1 anti-Jo-1 antibodies, } \\
\text { NMO-IgG neuromyelitis optica immunoglobulin G, NMOSD neuromyelitis optica spectrum disorders, OCB oligoclonal banding, RA33 anti-RA33 antibodies, RF rheumatoid } \\
\text { factor, Rib-P anti-ribosomal P protein antibodies, RNP anti-ribonucleoprotein antibodies, SCl-70 anti-topoisomerase I antibodies, Sm anti-Sm antibodies, SSA Anti-SSA/Ro } \\
\text { antibodies, SSB anti-SSB/La antibodies, T3 triiodothyronine, T4 thyroxine, TG anti-thyroglobulin antibodies, TSH thyroid-stimulating hormone, TPO anti-thyroid peroxidase } \\
\text { antibodies, WBC white blood cell. } \\
{ }_{*}^{* *} \mathrm{p}<0.001,{ }^{*} \mathrm{p}<0.05 \text {. }\end{array}$} \\
\hline
\end{tabular}

patients with autoimmune diseases $(\mathrm{p}<0.05)$. NMOIgG was detectable in $67.0 \%(71 / 115)$ NMOSD without autoimmune diseases and in $80.0 \%(32 / 40)$ NMOSD patients with autoimmune diseases $(\mathrm{p}=0.120)$.

NMOSD patients with autoimmune diseases were divided two groups with non-organ-specific and organ-specific autoimmune diseases. There were no statistical differences in CSF indexes between two groups $(\mathrm{p}>0.05)$. ANA, SSA, SSB seropositivity was significantly higher in NMOSD patients with non-organ-specific autoimmune diseases than in NMOSD patients with organ-specific autoimmune diseases $(\mathrm{p}<0.05)$, while anti-thyroid peroxidase antibodies (TPO) and TG seropositivity was significantly lower in NMOSD patients with non-organ-specific autoimmune diseases than in NMOSD patients with organ-specific autoimmune diseases $(\mathrm{p}<0.05)$. NMO-IgG was detectable in $81.8 \%(18 / 22)$ NMOSD with non-organ-specific autoimmune diseases, while in $77.8 \%(14 / 18)$ NMOSD patients with organ-specific autoimmune diseases $(p=0.751)$. No difference was found in other autoantibodies, complements, and thyroid hormones between two groups ( $\mathrm{p}>0.05)$.

As shown in Table 3 and Figure 2, NMOSD patients with autoimmune diseases had higher brain abnormalities than NMOSD without autoimmune diseases $(100.0 \%$ vs $67.0 \%, \mathrm{p}<0.001)$. However, there was no statistical difference in other MRI features between two group divided methods $(p>0.05)$. Longitudinally extensive transverse myelitis (LETM) lesions on spinal cord MRI were noted in $70.4 \%$ (81/115) NMOSD patients without autoimmune diseases and in 70.0\% (28/40) NMOSD patients with autoimmune diseases.

\section{Discussion}

In the present study, we found that NMOSD with autoimmune diseases have higher frequency of brain abnormalities than NMOSD without autoimmune diseases. We also found most clinical, laboratory, and MRI features do not differ significantly between different NMOSD subtypes divided by autoimmune diseases, while several CSF indexes, autoantibodies, and thyroid indexes differ significantly.

Motor deficit is typical feature of NMOSD. Furthermore, we found motor deficit was less frequency in patients with non-organ-specific autoimmune diseases. That finding was consistent with our spinal cord MRI findings that cervical cord lesions were less prevalent in patients with non-organspecific autoimmune diseases, though the difference was not statistically significant. Intractable hiccup and nausea (IHN) is rare and unique symptom in NMOSD. Several studies have reported IHN can be seen in 15.7-62.0\% NMO patients [11,12]. In our case series, $18.2-44.4 \%$ patients had IHN, though the difference was not statistically significant. Area postrema and nucleus tractus solitarius in the dorsomedial medulla and ventrolateral respiratory center involvement were the reasons for IHN. Previous report had found dorsal and pericanal regions of the medulla oblongata are frequently involved in NMO [13]. One of the explanations for this regional preference is the relative abundance of aquaporin-4 (AQP4) expression and compromised blood-brain barrier functions in these areas. Though clinical observations strongly suggested that many patients with NMO have neuropathic pain (NP), few systemic studies have focused on NP in NMOSD. Elsone et al. reported 27.3\% of NMO showed neuropathic pruritus, a special NP [14]. However, we describe the cases of $25.4 \%$ and $32.5 \%$ with NP in our patients. Kanamori et al. had found that pain in NMO is more frequent and severe than in multiple sclerosis [15]. NP may be related to the location of lesions in dorsal horn of spinal cord or spinal nucleus of trigeminal nerve or peri-aqueductal pathways [14]. Demographic and clinical features do not differ significantly between NMOSD without and with autoimmune diseases in our study.

In the current study, CSF WBC and protein, serum CRP and IgG were higher in NMOSD patients with autoimmune diseases. It suggests that the immune status is more active in patients with autoimmune diseases than that in patients without autoimmune diseases. Athough all NMOSD subtypes can found autoantibodies in the serum (especially ANA, SSA, SSB and RF in our study), different subtypes should have different autoantibodies seropositivity. These can be partly attributable to our inclusion criteria to recruit patients with different autoimmune diseases. In fact, ANAs are common in patients with NMOSD, especially in NMOSD with SLE/ 
Table 3 MRI features between NMOSD without and with autoimmune diseases, and between NMOSD with non-organ-specific and organ-specific autoimmune diseases

\begin{tabular}{|c|c|c|c|c|c|c|}
\hline & \multicolumn{2}{|l|}{ NMOSD } & \multirow[b]{2}{*}{$\mathbf{P}$} & \multicolumn{2}{|c|}{ NMOSD with autoimmune diseases } & \multirow[b]{2}{*}{$\mathbf{P}$} \\
\hline & $\begin{array}{l}\text { Without autoimmune } \\
\text { diseases }(n=115)\end{array}$ & $\begin{array}{l}\text { With autoimmune } \\
\text { diseases }(n=40)\end{array}$ & & Non-organ-specific $(n=22)$ & Organ-specific $(n=18)$ & \\
\hline Brain lesions, n (\%) & $77(67.0 \%)$ & $40(100.0 \%)$ & $<0.001^{* *}$ & $22(100.0 \%)$ & $18(100.0 \%)$ & - \\
\hline Brain lobes & $50(43.5 \%)$ & $23(57.5 \%)$ & 0.126 & $12(54.5 \%)$ & $11(61.1 \%)$ & 0.676 \\
\hline Basal ganglia & $15(13.0 \%)$ & $8(20.0 \%)$ & 0.286 & $6(27.3 \%)$ & $2(11.1 \%)$ & 0.382 \\
\hline Hypothalamic and thalamic & $12(10.4 \%)$ & $2(5.0 \%)$ & 0.302 & $1(4.5 \%)$ & $1(5.6 \%)$ & 1.000 \\
\hline Ventricle and aqueduct & $21(18.3 \%)$ & $10(25.0 \%)$ & 0.359 & $4(18.2 \%)$ & $6(33.3 \%)$ & 0.463 \\
\hline Midbrain & $5(4.2 \%)$ & $2(5.0 \%)$ & 0.864 & $1(4.5 \%)$ & $1(4.5 \%)$ & 1.000 \\
\hline Pons & $14(12.2 \%)$ & $9(22.5 \%)$ & 0.114 & $4(18.2 \%)$ & $5(27.8 \%)$ & 0.732 \\
\hline Medulla oblongata & $29(25.2 \%)$ & $13(32.5 \%)$ & 0.372 & $5(22.7 \%)$ & $8(44.4 \%)$ & 0.145 \\
\hline Cerebellum & $8(7.0 \%)$ & $1(2.5 \%)$ & 0.299 & $1(4.5 \%)$ & $0(00.0 \%)$ & 1.000 \\
\hline Spinal cord lesions, $\mathrm{n}(\%)$ & $88(76.5 \%)$ & $32(80.0 \%)$ & 0.650 & $17(77.3 \%)$ & $15(83.3 \%)$ & 0.634 \\
\hline Segments lesions & $5(0,17)$ & $6(0,15)$ & 0.486 & $4(0,17)$ & $6.5(0,15)$ & 0.603 \\
\hline LETM & $81(70.4 \%)$ & $28(70.0 \%)$ & 0.959 & $14(63.6 \%)$ & $14(77.8 \%)$ & 0.332 \\
\hline Cervical cord & $74(64.3 \%)$ & $27(67.5 \%)$ & 0.719 & $12(54.5 \%)$ & $15(83.3 \%)$ & 0.053 \\
\hline Thoracic cord & $62(53.9 \%)$ & $26(65.0 \%)$ & 0.223 & $14(63.6 \%)$ & $12(66.7 \%)$ & 0.842 \\
\hline Cervical and thoracic cord & $48(41.7 \%)$ & $23(57.5 \%)$ & 0.085 & $11(50.0 \%)$ & $12(66.7 \%)$ & 0.289 \\
\hline
\end{tabular}

Abbreviations: LETM longitudinally extensive transverse myelitis, MRI magnetic resonance imaging, NMOSD neuromyelitis optica spectrum disorders. ${ }^{* *} \mathrm{p}<0.001$.

SS [4]. NMO patients show concomitant autoantibodies, variably from 38 to $75 \%$, of which SSA is frequently detectable in NMO-IgG seropositive patients $[4,16]$. The finding was in agreement with our present study. In one study, autoantibody markers of SS or SLE were found in $47 \%$ patients with NMOSD [17]. In addition, recurrent myelitis and NMO show positivity for SSA, more frequently (77\%) than in monophasic disease (33\%) [18]. $\mathrm{NMO}$ can be associated with autoimmune thyroid diseases, including chronic thyroiditis, Graves' disease (GD) or benign thyroid tumours [19]. In the present study, all organ-specific autoimmune diseases patients were autoimmune thyroid diseases that might explain why TPO and TG seropositivity was frequent in that group. Previous study based on a large Japanese cohort reported autoimmune thyroid diseases were seen in 13.6\% NMOSD and were more often observed in the brain-dominant phenotype (40.0\%) [5]. The serum autoantibody NMO-IgG is a sensitive and specific marker for NMO. Its antigen is AQP4, the predominant water channel protein in the central nervous system [20]. Lennon and co-workers reported the presence of NMO-IgG was $91-100 \%$ seropositivity for NMO patients [20]. The autoantibody NMO-IgG is detectable also in patients with recurrent optic neuritis without myelitis and in a high proportion of patients with a single episode or recurrence of LETM without optic neuritis (NMOSD) [17]. NMO-IgG was detectable in $74-85 \%$ samples from patients with NMOSD $[21,22]$. In our case series, $67.0-81.8 \%$ patients had
NMO-IgG seropositivity, though the difference was not statistically significant. The reason why NMO-IgG positive in NMO/LETM frequently associated with autoimmune diseases is unclear. It has been speculated that the coexistence of the two disorders in the same patient might reflect a general autoimmune predisposition [23].

The frequency of brain MRI abnormalities is $50-85 \%$ in patients with NMO/NMOSD [24-28]. However, previous small study had reported all SS patients with NMOSD had several common brain abnormalities [29]. In present study, we found brain abnormalities in NMOSD with autoimmune diseases were more frequent than that in other NMOSD phenotypes. Among the brain lesions, asymptomatic lesions are more common; however, symptomatic brain involvement is also common [30]. Diencephalic or brainstem lesions adjacent to the third and fourth ventricles, longitudinal lesions of the internal capsule, and large extensive lesions have been suggested as characteristic lesions in NMO, even though they are not commonly observed [13,24,31]. Among the brain lesions, nonspecific lesions are very commonly found. They can be dot-like or patchy, $<3 \mathrm{~cm}$ in diameter, and located in the cerebral deep white matter, brainstem, or cerebellum [30]. The distribution of NMO-characteristic brain lesions corresponded to sites of high AQP4 expression, adjacent to the ventricular system at any level [13]. However, other NMO-characteristic brain lesions involved where AQP4 expression is not particularly high have also been reported $[27,30]$. In our case series, patients had a 

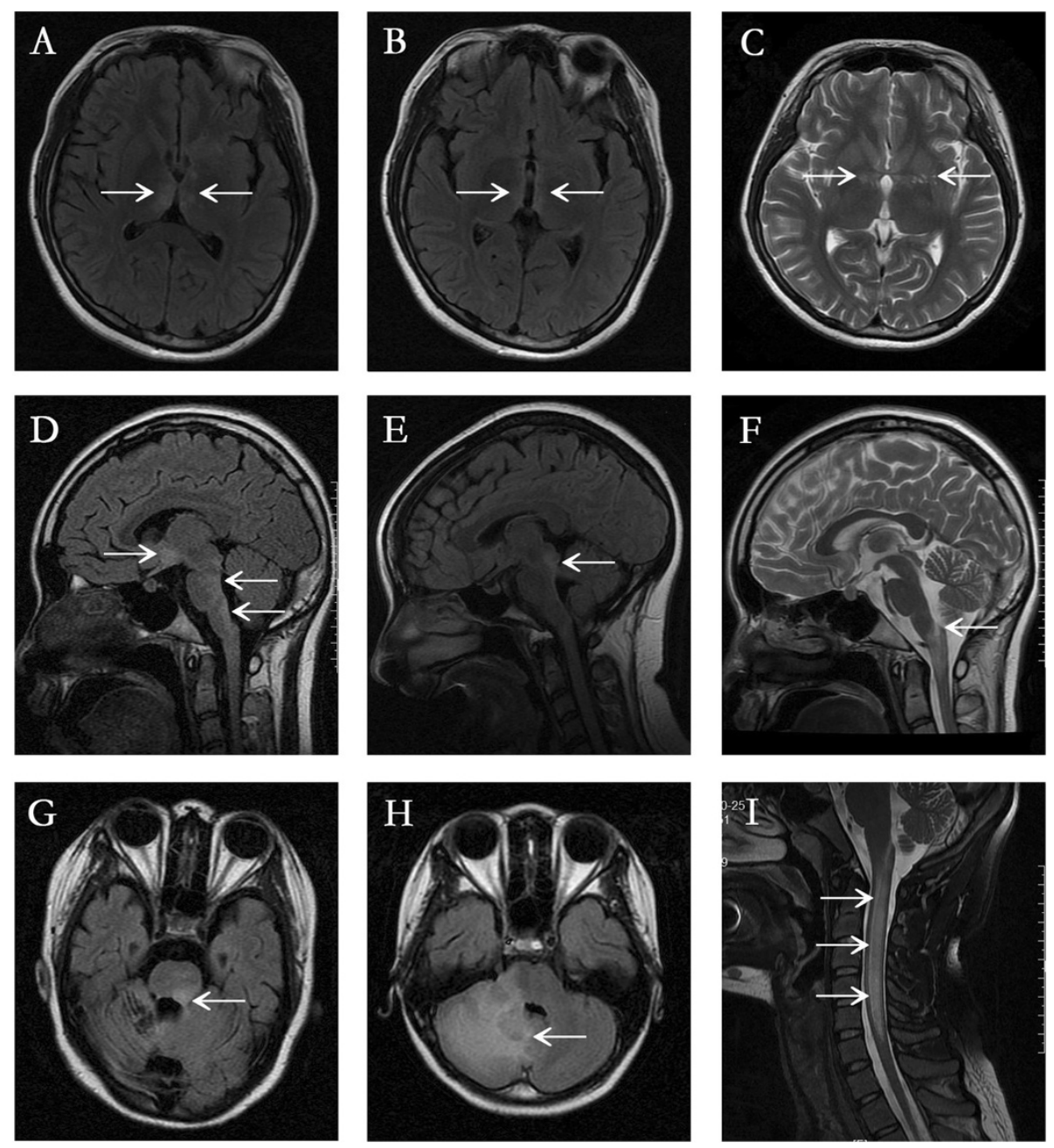

Figure 2 Representative magnetic resonance imaging (MRI) abnormalities (arrows) in NMOSD patients with autoimmune diseases.

(A) Bilateral thalamic lesions; (B) Bilateral hypothalamus lesions; (C) Basal ganglia lesion; (D) Hypothalamus and periventricular lesions; (E) Aqueduct of the midbrain lesion; (F) Cervico-medullary lesion; (G) Pons lesion; (H) Cerebellum lesion; (I) Longitudinally extensive transverse myelitis (LETM) lesions.

higher frequency of medulla oblongata lesions than that of midbrain and pons lesions. The result was consistent with our previous report showing that the medulla was the most common brainstem lesion location in NMO [32]. MRI of the spine cord has been regarded as the most useful diagnostic test in patients with suspected NMO [33]. The combination of NMO-IgG and a longitudinally extensive (three or more vertebral segments) cord lesion has been shown to be highly specific for the diagnosis [2]. Lesions are typically located in the cervical or thoracic cord with central or holocord involvement [34]. In our case series, although the difference was not statistically significant between groups, over 60\% NMOSD patients had LETM lesions on spine cord MRI.

Our study has some limitations. First, the number of NMOSD patients with autoimmune diseases included in our study is not sufficient. Second, the titer of NMO-IgG and autoantibodies was not tested, which result could strengthen our findings. Third, as a retrospective study, bias is inevitable. Furthermore, because the patients came from a single center, we were not able to validate our findings by applying them to a set of patients from other hospital. The p-values we reported were not corrected for multiple hypothesis testing. After post hoc analyses with Benjamini-Hochberg method, there were no statistical differences in CSF protein and glucose, AnuA and Sm seropositivity between NMOSD without and with autoimmune diseases. No difference was found in motor deficit and TPO between NMOSD with non-organ-specific and organ-specific autoimmune diseases.

\section{Conclusions}

In conclusion, the clinical, laboratory, and MRI features were similar between different NMOSD subtypes. NMOSD with autoimmune diseases have high frequency of brain abnormalities. 


\section{Competing interest}

The authors declare that there are no conflicts of interest.

\section{Authors' contributions}

Study design: all authors. Data collection: BJZ, YZ, YQW. Statistical analysis: BJZ, YZ. Manuscript preparation: all authors. All authors read and approved the final manuscript.

\section{Acknowledgements}

The authors thank Dr. Lan Guo at the Department of Medical Statistics and Epidemiology, School of Public health, Sun Yat-sen University for statistical assistance.

\section{Author details}

${ }^{1}$ Department of Neurology, The Third Affiliated Hospital of Sun Yat-sen University, No 600 Tianhe Road, Guangzhou, Guangdong 510630, China. ${ }^{2}$ Department of Rheumatology and Immunology, The Third Affiliated Hospital of Sun Yat-sen University, Guangzhou, China.

\section{Received: 7 May 2014 Accepted: 4 August 2014}

Published: 19 August 2014

\section{References}

1. Wingerchuk DM, Lennon VA, Lucchinetti CF, Pittock SJ, Weinshenker BG: The spectrum of neuromyelitis optica. Lancet Neurol 2007, 6:805-815.

2. Wingerchuk DM, Lennon VA, Pittock SJ, Lucchinetti CF, Weinshenker BG: Revised diagnostic criteria for neuromyelitis optica. Neurology 2006, 66:1485-1489.

3. Lennon VA, Wingerchuk DM, Kryzer TJ, Pittock SJ, Lucchinetti CF, Fujihara K, Nakashima I, Weinshenker BG: A serum autoantibody marker of neuromyelitis optica: distinction from multiple sclerosis. Lancet 2004, 364:2106-2112.

4. Pittock SJ, Lennon VA, de Seze J, Vermersch P, Homburger HA, Wingerchuk DM, Lucchinetti CF, Zephir H, Moder K, Weinshenker BG: Neuromyelitis optica and non organ-specific autoimmunity. Arch Neurol 2008, 65:78-83.

5. Nagaishi A, Takagi M, Umemura A, Tanaka M, Kitagawa Y, Matsui M, Nishizawa M, Sakimura K, Tanaka K: Clinical features of neuromyelitis optica in a large Japanese cohort: comparison between phenotypes. J Neurol Neurosurg Psychiatry 2011, 82:1360-1364.

6. Leite MI, Coutinho E, Lana-Peixoto M, Apostolos S, Waters P, Sato D, Melamud L, Marta M, Graham A, Spillane J, Villa AM, Callegaro D, Santos E, da Silva AM, Jarius S, Howard R, Nakashima I, Giovannoni G, Buckley C, Hilton-Jones D, Vincent A, Palace J: Myasthenia gravis and neuromyelitis optica spectrum disorder: a multicenter study of 16 patients. Neurology 2012, 78:1601-1607.

7. Hochberg MC: Updating the American College of Rheumatology revised criteria for the classification of systemic lupus erythematosus. Arthritis Rheum 1997, 40:1725.

8. Shiboski SC, Shiboski CH, Criswell L, Baer A, Challacombe S, Lanfranchi H, Schiodt M, Umehara H, Vivino F, Zhao Y, Dong Y, Greenspan D, Heidenreich AM, Helin P, Kirkham B, Kitagawa K, Larkin G, Li M, Lietman T, Lindegaard J, McNamara N, Sack K, Shirlaw P, Sugai S, Vollenweider C, Whitcher J, Wu A, Zhang S, Zhang W, Greenspan J, et al: American College of Rheumatology classification criteria for Sjogren's syndrome: a data-driven, expert consensus approach in the Sjogren's International Collaborative Clinical Alliance cohort. Arthritis Care Res 2012, 64:475-487.

9. Aletaha D, Neogi T, Silman AJ, Funovits J, Felson DT, Bingham CO 3rd, Birnbaum NS, Burmester GR, Bykerk VP, Cohen MD, Combe B, Costenbader KH, Dougados M, Emery P, Ferraccioli G, Hazes JM, Hobbs K, Huizinga TW, Kavanaugh A, Kay J, Kvien TK, Laing T, Mease P, Menard HA, Moreland LW, Naden RL, Pincus T, Smolen JS, Stanislawska-Biernat E, Symmons D, et al: Rheumatoid arthritis classification criteria: an American College of Rheumatology/European League Against Rheumatism collaborative initiative. Arthritis Rheum 2010, 2010(62):2569-2581.

10. Mosca M, Tani C, Carli L, Bombardieri S: Undifferentiated CTD: a wide spectrum of autoimmune diseases. Best Pract Res Clin Rheumatol 2012, 26:73-77.

11. Takahashi T, Miyazawa I, Misu T, Takano R, Nakashima I, Fujihara K, Tobita M, Itoyama Y: Intractable hiccup and nausea in neuromyelitis optica with anti-aquaporin-4 antibody: a herald of acute exacerbations. J Neurol Neurosurg Psychiatry 2008, 79:1075-1078.
12. Misu T, Fujihara K, Nakashima I, Sato S, Itoyama Y: Intractable hiccup and nausea with periaqueductal lesions in neuromyelitis optica. Neurology 2005, 65:1479-1482.

13. Pittock SJ, Weinshenker BG, Lucchinetti CF, Wingerchuk DM, Corboy JR, Lennon VA: Neuromyelitis optica brain lesions localized at sites of high aquaporin 4 expression. Arch Neurol 2006, 63:964-968.

14. Elsone L, Townsend T, Mutch K, Das K, Boggild M, Nurmikko T, Jacob A: Neuropathic pruritus (itch) in neuromyelitis optica. Mult Scler 2013, 19:475-479.

15. Kanamori $Y$, Nakashima I, Takai $Y$, Nishiyama S, Kuroda H, Takahashi T, Kanaoka-Suzuki C, Misu T, Fujihara K, Itoyama Y: Pain in neuromyelitis optica and its effect on quality of life: a cross-sectional study. Neurology 2011, 77:652-658

16. de Seze J, Stojkovic T, Ferriby D, Gauvrit JY, Montagne C, Mounier-Vehier F, Verier A, Pruvo JP, Hache JC, Vermersch P: Devic's neuromyelitis optica: clinical, laboratory, MRI and outcome profile. J Neurol Sci 2002, 197:57-61.

17. Jacob A, McKeon A, Nakashima I, Sato DK, Elsone L, Fujihara K, de Seze J: Current concept of neuromyelitis optica (NMO) and NMO spectrum disorders. J Neurol Neurosurg Psychiatry 2013, 84:922-930.

18. Hummers LK, Krishnan C, Casciola-Rosen L, Rosen A, Morris S, Mahoney JA, Kerr DA, Wigley FM: Recurrent transverse myelitis associates with anti-Ro (SSA) autoantibodies. Neurology 2004, 62:147-149.

19. Wingerchuk DM, Weinshenker BG: The emerging relationship between neuromyelitis optica and systemic rheumatologic autoimmune disease. Mult Scler 2012, 18:5-10.

20. Lennon VA, Kryzer TJ, Pittock SJ, Verkman AS, Hinson SR: IgG marker of optic-spinal multiple sclerosis binds to the aquaporin-4 water channel. J Exp Med 2005, 202:473-477.

21. Weinshenker BG, Wingerchuk DM, Vukusic S, Linbo L, Pittock SJ, Lucchinetti CF, Lennon VA: Neuromyelitis optica lgG predicts relapse after longitudinally extensive transverse myelitis. Ann Neurol 2006 59:566-569.

22. Matiello M, Lennon VA, Jacob A, Pittock SJ, Lucchinetti CF, Wingerchuk DM, Weinshenker BG: NMO-lgG predicts the outcome of recurrent optic neuritis. Neurology 2008, 70:2197-2200.

23. Jarius S, Jacobi C, de Seze J, Zephir H, Paul F, Franciotta D, Rommer P, Mader S, Kleiter I, Reindl M, Akman-Demir G, Seifert-Held T, Kristoferitsch W, Melms A, Wandinger KP, Wildemann B: Frequency and syndrome specificity of antibodies to aquaporin-4 in neurological patients with rheumatic disorders. Mult Scler 2011, 17:1067-1073.

24. Pittock SJ, Lennon VA, Krecke K, Wingerchuk DM, Lucchinetti CF, Weinshenker BG: Brain abnormalities in neuromyelitis optica. Arch Neurol 2006, 63:390-396.

25. Cabrera-Gomez JA, Quevedo-Sotolongo L, Gonzalez-Quevedo A, Lima S, Real-Gonzalez Y, Cristofol-Corominas M, Romero-Garcia K, Ugarte-Sanchez C, Jordan-Gonzalez J, de la Nuez JE, Lahera JG, Tellez R, Pedroso-Ibanez I, Roca RR, Cabrera-Nunez AY: Brain magnetic resonance imaging findings in relapsing neuromyelitis optica. Mult Scler 2007, 13:186-192.

26. Kim W, Kim SH, Lee SH, Li XF, Kim HJ: Brain abnormalities as an initial manifestation of neuromyelitis optica spectrum disorder. Mult Scler 2011, 17:1107-1112

27. Wang F, Liu Y, Duan Y, Li K: Brain MRI abnormalities in neuromyelitis optica. Eur J Radiol 2011, 80:445-449.

28. Matthews L, Marasco R, Jenkinson M, Kuker W, Luppe S, Leite MI, Giorgio A, De Stefano N, Robertson N, Johansen-Berg H, Evangelou N, Palace J: Distinction of seropositive NMO spectrum disorder and MS brain lesion distribution. Neurology 2013, 80:1330-1337.

29. Min JH, Kim HJ, Kim BJ, Lee KW, Sunwoo IN, Kim SM, Kim BJ, Kim SH, Park MS, Waters P, Vincent A, Sung JJ, Lee KH: Brain abnormalities in Sjogren syndrome with recurrent CNS manifestations: association with neuromyelitis optica. Mult Scler 2009, 15:1069-1076.

30. Kim W, Park MS, Lee SH, Kim SH, Jung IJ, Takahashi T, Misu T, Fujihara K, Kim HJ: Characteristic brain magnetic resonance imaging abnormalities in central nervous system aquaporin-4 autoimmunity. Mult Scler 2010, 16:1229-1236

31. Nakashima I, Fujihara K, Miyazawa I, Misu T, Narikawa K, Nakamura M, Watanabe S, Takahashi T, Nishiyama S, Shiga Y, Sato S, Weinshenker BG, Itoyama Y: Clinical and MRI features of Japanese patients with multiple sclerosis positive for NMO-lgG. J Neurol Neurosurg Psychiatry 2006, 77:1073-1075. 
32. Lu Z, Zhang B, Qiu W, Kang Z, Shen L, Long Y, Huang J, Hu X: Comparative brain stem lesions on MRI of acute disseminated encephalomyelitis, neuromyelitis optica, and multiple sclerosis. PLoS One 2011, 6:e22766.

33. Wingerchuk DM: Diagnosis and treatment of neuromyelitis optica. Neurologist 2007, 13:2-11.

34. Downer JJ, Leite MI, Carter R, Palace J, Kuker W, Quaghebeur G: Diagnosis of neuromyelitis optica (NMO) spectrum disorders: is MRI obsolete? Neuroradiology 2012, 54:279-285.

doi:10.1186/s12883-014-0162-7

Cite this article as: Zhang et al: Neuromyelitis optica spectrum disorders without and with autoimmune diseases. BMC Neurology 2014 14:162.

\section{Submit your next manuscript to BioMed Central and take full advantage of:}

- Convenient online submission

- Thorough peer review

- No space constraints or color figure charges

- Immediate publication on acceptance

- Inclusion in PubMed, CAS, Scopus and Google Scholar

- Research which is freely available for redistribution 